\title{
Comparative Analysis of Houses Built from Insulating Concrete Formwork - case Study
}

\author{
Daniela Mačková, Marcela Spišáková \\ Technical University of Košice \\ Civil Engineering Faculty, Institute of Construction Technology and Management \\ e-mail:daniela.mackova@tuke.sk, marcela.spisakova@tuke.sk
}

\begin{abstract}
More and more, people are looking to build and live in different ways. They want houses with a high standard of living and reasonable production and maintenance costs. However, they also want to build a way that does not adversely affect their quality of life. Currently, the using of modern methods of construction (MMC) expands consistently year on year. MMC include prefabricated products made in the factory and also new methods of building that are site-based and they are regarded as a means of achieving higher quality, reducing time spent onsite, increasing safety and overcoming skills shortages in the industry. Aim of this paper is to analyze and compare, trough case study, technical, cost and technological parameters of house built by modern method of construction (from insulating concrete formwork) and by traditional method (from brick system). The subject of case study is house modeled in two variants of insulating concrete formwork and a variant bricks and ceiling system. In conclusion, there is selected optimal method and system for house construction through multicriteria optimization.
\end{abstract}

Key words: modern methods of construction, insulating concrete formwork, Durisol, Medmax, Porotherm

\section{Introduction}

The construction industry all over the world is under great pressure to improve its performance. Increasingly, new construction technologies are emerging and they are called modern methods of construction (MMC). Traditional buildings (TB) and buildings constructed by modern method of construction are not as diametrically opposed as black versus white, and there are clear overlaps between them. In spite of that, it is possible to define the main distinctions between traditional buildings and buildings constructed by modern method [1] (Tab.1).

The term of modern method of construction was established in the UK as a common label for the construction methods of construction based on the off-site technologies (prefabrication elements or parts of constructions are made off-site and then transported and assembled on site) and innovative on-site technologies (parts of construction elements are produced in the 
factory, but its functional location is completed on the site). Zupova and Kozlovska [2] says MMC has a great potential to improve the efficiency of construction production, quality, customer satisfaction, environmental impact, sustainability and predictability of construction design delivery in particular terms.

Table 1: Distinctions between TB and buildings constructed by MMC [1]

\begin{tabular}{|l|l|}
\hline Traditional buildings & $\begin{array}{l}\text { Buildings constructed by modern } \\
\text { method }\end{array}$ \\
\hline $\begin{array}{l}\text { High external clarity } \\
\text { Handling uncertainties/Agile production }\end{array}$ & $\begin{array}{l}\text { Low external clarity } \\
\text { Aims to reduce uncertainties/standardise } \\
\text { production }\end{array}$ \\
Flexibility (product) & $\begin{array}{l}\text { Standardisation (product) } \\
\text { Standardisation (process) } \\
\text { Flexibility (process) }\end{array}$ \\
Craftsmanship & Industrialisation, factory-workers \\
\hline
\end{tabular}

The construction sector is responsible for resource depletion and environmental damage. The comparison of traditional and modern buildings in relation to environmentally-efficient parameters can be found in [3]. It is recognized for its high-energy consumption, global greenhouse gas emissions, solid waste generation and pollution at all levels. The records shows that building activities are responsible for exploring and consuming about $40 \%$ of the natural resources such as stone, sand, wood and water [4]. The depletion of natural resources due to the huge demand for energy and construction materials for the ever-increasing population and demand in the construction sector has caused irrevocable ecological imbalance. The environmental impact of human activities and the anxiety about decreasing energy resources warrants greater attention globally to ensure sustainable development [5]. The growing necessity to save material and energy resources, together with an increasing concern over the environmental issues and uncertainties on the evolution of the economy, have impelled minimalist approaches to Architecture and Engineering. This created a new necessity for reducing, to the minimum necessary expression, the used building materials and elements [6]. Global urbanization and the ever increasing demands for higher living standards among the world's population are underlying causes for the need to develop urban infrastructures, negatively influencing the necessary balance between the built and natural environments [7]. Based on the increasing demands for the implementation and use of buildings is also necessary to apply modern technological processes which aim at effective use of building materials. One of them is insulating concrete formwork (ICF). ICFs offer superior energy performance and whole life costs combined with excellent durability. The combination of concrete delivered in exact quantities by truck mixer and ICFs simply clipped together offers clean safe building sites with almost zero wastage [8].

This article presents the analysis of two selected ICFs (as modern method of construction) and the results are compared to traditional technology of brick system. 


\section{Modern insulating concrete formwork versus traditional brick system}

Insulating concrete formwork otherwise known as permanently insulated formwork is an insulated in-situ concrete system of building that is quick to construct and offers levels of performance significantly better than that available from slower, more traditional approaches to building. It is recognized as an MMC system (modern method of construction). ICF is based on hollow lightweight block components that lock together without intermediate bedding materials, such as mortar, to provide a formwork system into which concrete is poured. There are several possibilities of ICFs material. Two selected ICF systems - Durisol and Medmax are analyzed in this article.

Clay bricks and roof tiles are among the oldest building materials in the world and still extremely popular. Clay building materials can be used for a variety of applications. They can be used for walls, facades and roofs as well as for gardens, terraces and open spaces. Clay tiles and bricks can be used almost anywhere and for all architectural styles, whether for the construction of single family houses or apartment blocks, office or public buildings. Brick system Porotherm is analyzed in this article.

\subsection{Durisol units}

Durisol units are formed from using cement-bonded wood fibre material. Composed of a specially graded recycled waste wood, it is initially chipped into wood fibre and then mineralized and bonded together with a combination of Cem 1 cement and Cenin; a cement substitute that has a very low carbon content. Recycled Durisol units are also used as part of the mixing process, as it acts as filler. For internal wall units, limestone grit is added, which helps with acoustic properties. The cement-bonded wood fibre mix is then molded and stamped out to form the many shapes that comprise the full range of Durisol units. Once the Durisol units have been produced, external wall units are filled with either graphite polystyrene or PIR. Durisol cement-bonded wood fibre insulated concrete forms are porous, lightweight and very durable. They do not rot nor decay. Our insulated concrete forms are also vermin and insect proof and will not support fungus growth. Durisol ICF forms are environmentally safe, do not contain nor emit any toxic elements, and are fully recyclable. They contain no plastic, foams or polystyrenes [9].

\subsection{Medmax blocks}

Medmax blocks consist of two wall units which are connected by eight pieces of plastic couplings into a block up on the site. The possibility of dismantling protects the environment by reducing material volumes. Dismantled block consumes only a half of space during transport. The blocks are connected to each other with dry connection by cross-latch. It creates a compact concrete wall, without thermal bridges and with insulation on each side. Concreting can also takes place during frost because of duplex insulation walls. Building blocks are accurate and light, so it is not necessary to have lifting equipment on site [10]. 


\subsection{Porotherm blocks}

Porotherm blocks are made from clay and have a high recycled material content (typically 20$30 \%$ mineral spoil, sawdust and paper). The blocks are extruded, dried and fired in a highly efficient manufacturing process. After the products have been fired, the block height is precision ground to an accuracy of $+/-0.5 \mathrm{~mm}$. This enables true thin-joint technology in construction. Part of the secret to the thermal efficiency of the products is in the multiperforation patterns and pore structure which combine to provide thermal insulation and vapour permeability properties [11].

\section{METHODOLOGY}

Aim of this paper is to analyze and compare, through case study, technical, cost and technological parameters of house built by modern method of construction (from insulating concrete formwork) and by traditional method (from brick system) and to choose optimal construction method for house, built from these three selected construction systems, respecting potential investor's requirements. Multicriteria optimization is used. Parameters of multicriteria optimization and their weight are selected according to questionnaire survey.

\subsection{Questionnaire survey}

The aim of questionnaire survey (by interview) in this study was to find out importance of technical, cost and technological parameters of house construction from potential investor perspective. Respondents were randomly selected on the street, mainly in towns from Kosice and Presov regions and they were asked twelve questions. Introduction to the questionnaire was focused on general information about the respondent. The main part was focused on their requirements for house they would like to live in. Their task was to identify importance of selected construction parameters. A five-point Likert-type scale was used, where 1 represented "very important for me" and 5 stood for "not important for me". Forty-four questionnaires were completed. Breakdown of respondents by age and by gender is shown on Fig.1.

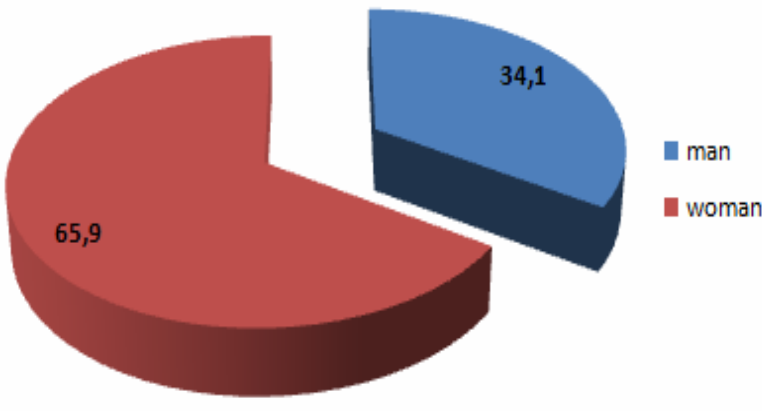

a)

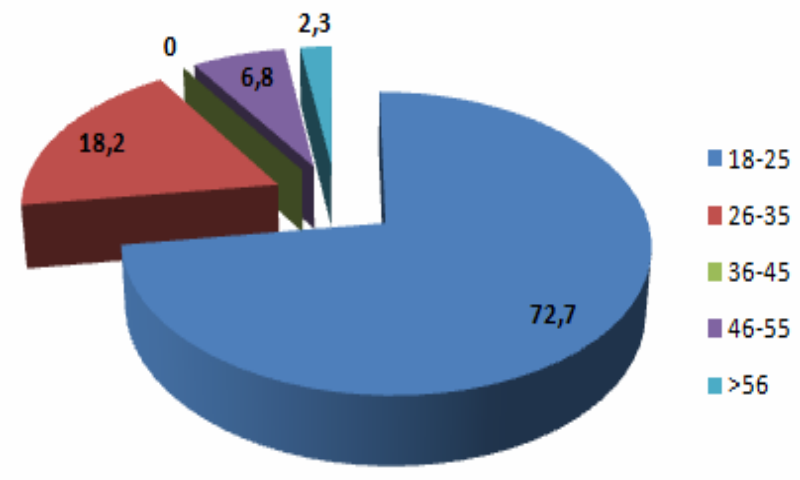

b)

Figure 1: Breakdown of respondents a) by gender b) by age in percentage 


\subsection{Parameters of multicriteria optimization and their weight}

Respondents were asked to identify importance (on the five-point Likert-type scale) of selected parameters: construction cost, maintenance cost (heating cost), construction time, construction material, technologically demanding construction, better use of floor area. According to results the weight of parameters was determined (Table 2). Parameters not mentioned in the table 2 have null importance for respondents.

Table 2: Importance weight of construction parameters

\begin{tabular}{|l|c|}
\hline parameter & weight [\%] \\
\hline construction cost & 50,0 \\
heating cost & 33,4 \\
better use of floor area & 16,6 \\
\hline
\end{tabular}

Multicrieria optimization is used for the optimal construction method selection respecting determined importance weight of construction parameters.

\subsection{Subject of case study}

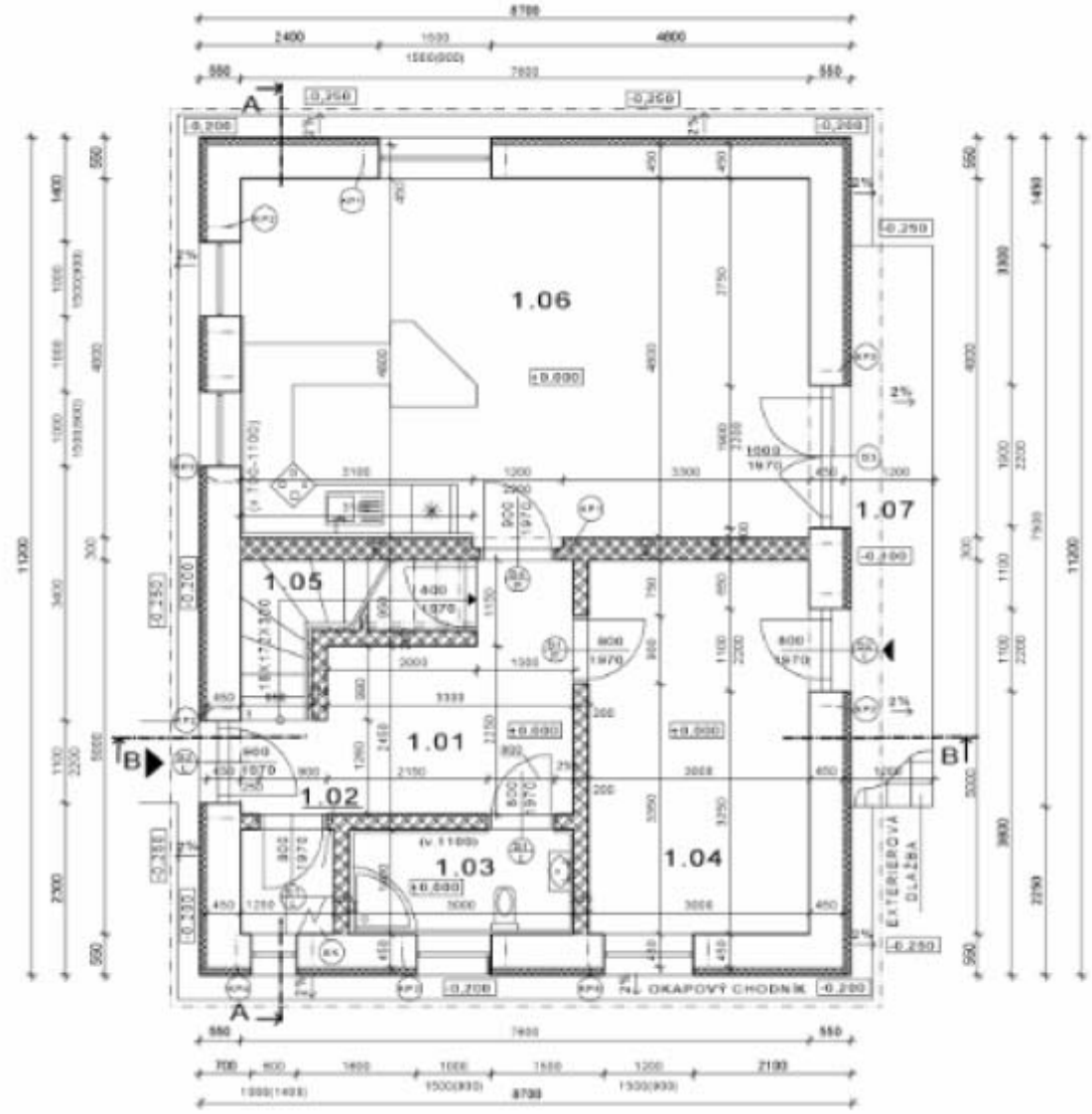

Figure 2: Ground plan of modeled house 
The subject of case study is house (Fig.2,3) modeled in mentioned three construction variants. House has two stories and gross floor area is $187 \mathrm{~m}^{2}$. House does not have underground storey.

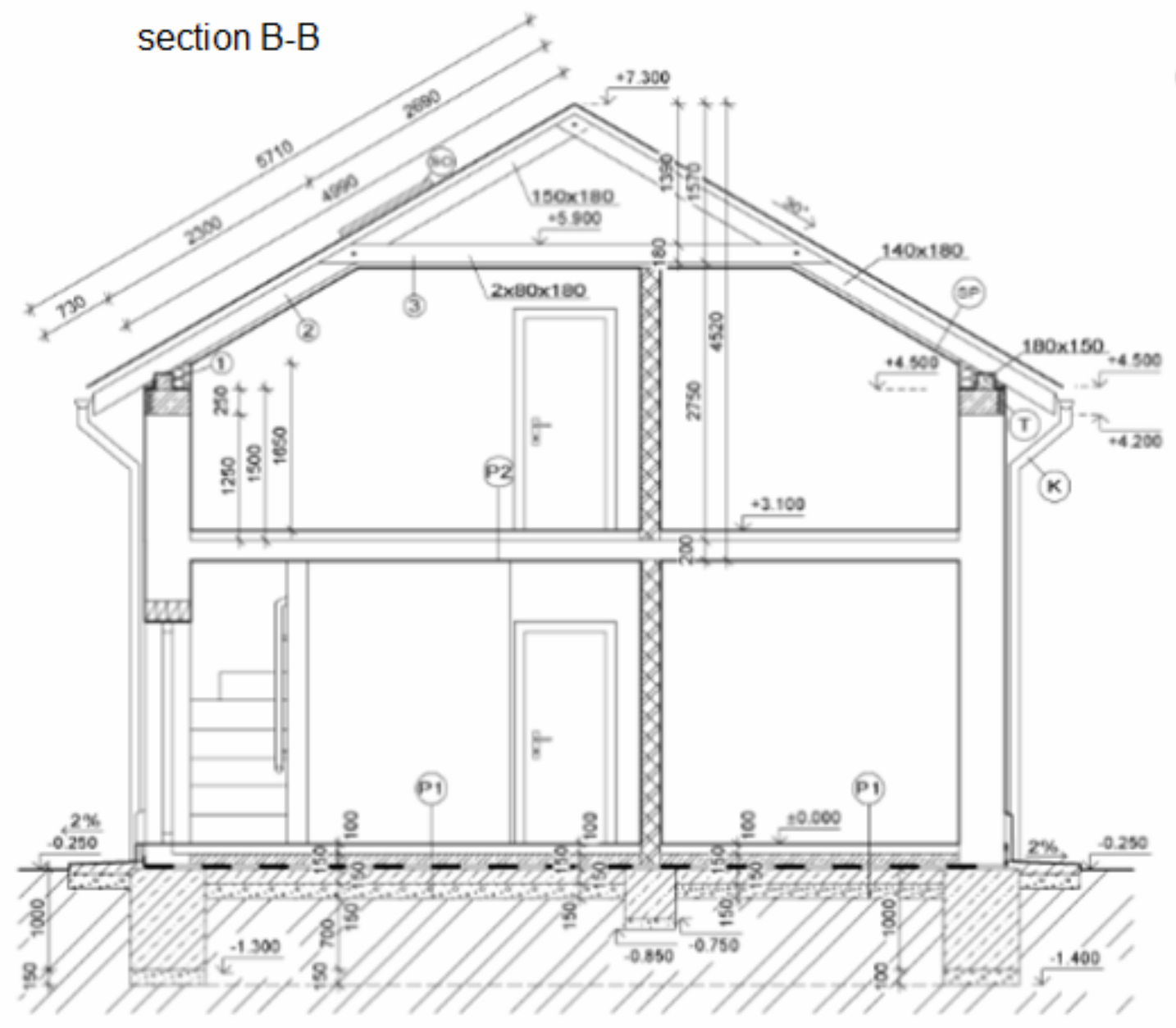

Figure 3: Section B-B of modeled house

It was done budget of construction material and work, calculation of heating cost and the floor area calculation for all three systems of house. According to these documents, it was able to quantify selected objectives in multicriteria optimization process (Tab.3).

Table 3: Quantification of multicriteria objectives

\begin{tabular}{|l|c|c|c|}
\hline \multirow{2}{*}{ House variant } & \multicolumn{3}{|c|}{ Objectives } \\
\cline { 2 - 4 } & Construction cost [EUR] & Heating cost [EUR/year] & Floor area $\left[\mathrm{m}^{2}\right]$ \\
\hline Durisol & 67995 & 515 & 145 \\
\hline Medmax & 71829 & 477 & 147 \\
\hline Porotherm & 74998 & 520 & 134 \\
\hline
\end{tabular}


Multicriteria optimization is an area of multiple criteria decision making, that is concerned with mathematical optimization problems involving more than one objective function to be optimized simultaneously. Multicriteria optimization is applied in many fields of science, including engineering, economics and logistics where optimal decisions need to be taken in the presence of trade-offs between two or more conflicting objectives.

\section{RESULTS AND DISCUSION}

Aim of this study is to choose optimal construction method for house (mentioned in section 3.3) from three selected construction systems - Durisol, Medmax and Porotherm respecting potential investor's requirements. Three multicriteria optimization objectives and their weight were selected according to questionnaire survey and the result of optimization is shown in Table 5.

Next, it was necessary to calculate coefficient $k_{\mathrm{ij}}$ (Table 4) for all objectives within all house variants. Coefficient $k_{\mathrm{ij}}$ expresses the rate at which the variant is closer to the theoretical optimal variant (overbased variant).

Table 4: Coefficient $k_{\mathrm{ij}}$ calculation

\begin{tabular}{|c|c|c|c|}
\hline \multirow{2}{*}{ House variant } & \multicolumn{3}{|c|}{ Objectives } \\
\cline { 2 - 4 } & Construction cost [EUR] & Heating cost [EUR/year] & Floor area $\left[\mathrm{m}^{2}\right.$ ] \\
\hline Durisol & 67995 & 515 & 145 \\
\hline Medmax & 71829 & 477 & 147 \\
\hline Porotherm & 74998 & 520 & 134 \\
\hline Overbased & 67995 & 477 & 147 \\
\hline \multicolumn{3}{|c|}{ Coefficient $k_{\mathrm{ij}}$} \\
\hline Durisol & 1 & 0,9264 & 0,9861 \\
\hline Medmax & 0,9466 & 1 & 1 \\
\hline Porotherm & 0,9066 & 0,9183 & 0,9139 \\
\hline
\end{tabular}

Finally, objective weight (weight in percentace/100) and coefficient $k_{\mathrm{ij}}$ are multiplied. Sum of all numbers in rows gives variant utility. Variant with the higher utility is optimal variant respecting selected objectives.

Table 5: Variant utility calculation

\begin{tabular}{|c|c|c|c|c|}
\hline Objectives & $\begin{array}{l}\text { Construction } \\
\text { cost }\end{array}$ & Heating cost & Floor area & \multirow{4}{*}{ Variant utility } \\
\hline \multirow{3}{*}{ House variant } & \multicolumn{3}{|c|}{ Objective weight } & \\
\hline & 0,5 & 0,334 & 0,166 & \\
\hline & \multicolumn{3}{|c|}{ Objective weight and coefficient $k_{\mathrm{ij}}$ multiplying } & \\
\hline Durisol & $\mathbf{0 , 5 0 0 0}$ & $\mathbf{0 , 3 0 8 8}$ & 0,1642 & $\mathbf{0 , 9 7 3 0}$ \\
\hline Medmax & 0,4733 & 0,3334 & 0,1666 & 0,9733 \\
\hline Porotherm & 0,4533 & 0,3061 & 0,1522 & 0,9116 \\
\hline
\end{tabular}


Based on multicriteria optimization it can be concluded that, with respecting potential investor's requirements, construction system Durisol is optimal for house construction.

\section{CONCLUSION}

Aim of this case study was to analyze and compare technical, cost and technological parameters of house built by modern method of construction (from insulating concrete formwork) and by traditional method (from brick system) and to choose optimal construction method for house, built from three selected construction systems, respecting potential investor's requirements. Objectives of multicriteria optimization and their weight were selected according to questionnaire survey. Finally, multicriteria optimization was done. As an optimal variant for house construction was chosen system Durisol - insulating concrete formwork system.

\section{Acknowledgements}

The article presents a partial research result of project VEGA - 1/0677/14 "Research of construction efficiency improvement through MMC technologies".

\section{References}

[1] Engstrom S. et al. (2009). Competitive impact of industrialised building - in search for explanations to the current state. Procs 25th Annual ARCOM Conference, Nottingham, UK, Association of Researchers in Construction Management, pp 413-24.

[2] Župová, L. \& Kozlovská, M. (2013). Modern methods of construction as a challenge for energy efficiency buildings. 13th International Multidisciplinary Scientific Geoconference and EXPO, SGEM 2013; Albena; Bulgaria; 16 June 2013 through 22 June 2013., p.677-684.

[3] Leśniak A., Zima K., Comparison of traditional and ecological wall systems using the AHP method. In: 15th International Multidisciplinary Scientific GeoConference SGEM 2015, June 18-24, 2015, Book5 Vol. 3, pp. 157-164.

[4] Mateus R \& Bragança L. (2010). Building technologies for sustainable construction. Porto: Ecopy.

[5] U.S. Energy Information Administration (EIA), Monthly Energy Review, 2014, Retrieved from: http://www.eia.gov/totalenergy/data/monthly/pdf/sec2 3.pdf

[6] Mateus R. et al. (2013). Sustainability assessment of an innovative lightweight building technology for partition walls - Comparison with conventional technologies. In: Building and Environment 67, pp 147-159.

[7] Neiva S, Mateus R \& Bragança L. (2012). Environmental LCA for building technologies. In: Proceedings of the international conference BSA 2012. Porto, Portugal:Greenlines Institute for a Sustainable Built Environment and University of Minho.

[8] http://www.icfa.org.uk/icf-benefits/the-environment-and-icf/

[9] http://www.durisoluk.com/building-and-sustainable-credentials/passivhaus/

[10] http://www.pasivnydom.sk/obvodovy-plast/medmax/

[11] http://www.rgbltd.co.uk/userfiles/cms/Building_Materials/Wienerberger_Porotherm_/Porother m.pdf 